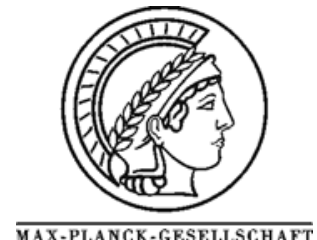

Originally published as:

"Morphology changes of Pt-foil catalyst induced by temperaturecontrolled ammonia oxidation near atmospheric pressure"

Ralph Kraehnert, Manfred Baerns

Applied Catalysis A: General 327 (2007) 73-81

doi:10.1016/j.apcata.2007.04.031 


\title{
Morphology changes of Pt-foil catalyst induced by temperature-controlled ammonia oxidation near atmospheric pressure
}

\author{
R. Kraehnert ${ }^{*}$, M. Baerns ${ }^{1}$ \\ Leibniz-Institute for Catalysis at the University of Rostock, Branch Berlin (former ACA) Richard-Willstaetter street 12, D-12489 Berlin, Germany
}

Received 23 January 2007; received in revised form 5 April 2007; accepted 23 April 2007

Available online 29 April 2007

\begin{abstract}
Reaction-induced changes of the morphology of a Pt foil catalyst during ammonia oxidation were investigated in a temperature-controlled way for partial pressures of oxygen and ammonia around 4.5 and $3 \mathrm{kPa}$, respectively, and at temperatures between 20 and $700{ }^{\circ} \mathrm{C}$. The presence of the feed mixture (ammonia and oxygen) was required to induce surface roughening. Moreover, the reaction temperature controlled the type of restructuring of the Pt surface, that is, either into rows of parallel facets where facet size increased with temperature, or as bulky microcrystals protruding from the surface. Surprisingly, reaction-induced surface faceting was already observed at $286{ }^{\circ} \mathrm{C}$. Between 286 and $374{ }^{\circ} \mathrm{C}$ adsorbateenhanced surface diffusion of Pt is suggested to account for the surface restructuring well below temperatures reported for significant Pt transport through the gas phase via volatile $\mathrm{PtO}_{x}$.
\end{abstract}

(C) 2007 Elsevier B.V. All rights reserved.

Keywords: Catalytic ammonia oxidation; Platinum; Surface morphology; Restructuring; Faceting; SEM

\section{Introduction}

Selective oxidation of ammonia on Pt-based alloy catalysts is the first step of the Ostwald process dominating the industrial production of nitric acid. The surface of the applied Pt catalysts is heavily reconstructed within hours and days during the reaction $[1,2]$. Since similar reaction-induced surface reconstructions have been reported also for the catalytic oxidation of hydrogen, ethane, and propane [3], the respective processes were summarized under the term of "catalytic etching".

Depending on pressure, temperature, catalyst composition, and time of exposure to catalytic ammonia oxidation, the surface of Pt-based catalysts reconstructs into rows of facets and pits [4], and later on into bulky structures resembling the shape of cauliflowers [5-7]. Such extensive reconstruction of the surface of the industrially applied Pt-Rh alloy gauzes leads to loss of catalytic material, mechanical degradation, and finally to the collapse of the catalyst wires. Special gauzes

\footnotetext{
* Corresponding author. Tel.: +49 306392 4438; fax: +49 3063924350 .

E-mail address: kraehnert@aca-berlin.de (R. Kraehnert).

${ }^{1}$ Present address: Fritz-Haber-Institut, Faradayweg 4-6, 14195 Berlin, Germany.
}

0926-860X/\$ - see front matter (C) 2007 Elsevier B.V. All rights reserved. doi:10.1016/j.apcata.2007.04.031 located downstream of the active package, usually made of palladium or Pd-Au alloys, can be applied to catch part of the platinum which is otherwise lost [8].

Catalytic etching of $\mathrm{Pt}$ catalysts during ammonia oxidation was not detected at pressures below $15 \mathrm{~Pa}$ even after extended periods of catalyst operation $[9,10]$, an observation confirmed by our recent study on the influence of pressure on structural and catalytic properties of different platinum catalysts [11]. At higher reactant partial pressures (kPa range), the reconstruction of Pt surfaces has been studied during catalytic ammonia oxidation at temperatures above $600{ }^{\circ} \mathrm{C}$ on polycrystalline platinum in the shape of wires $[4,6,7,12]$, gauzes $[5,13,14]$, and spheres [15]. Evaporation of Pt-containing species, their transport in the gas phase, and subsequent decomposition and redeposition of $\mathrm{Pt}$ on the surface were suggested as key steps in the catalytic etching process [16,17]. Different transport mechanisms were proposed:

(1) Phillips et al. [18-20] studied the oxidation of hydrogen and ethene on platinum catalysts, and proposed that $\mathrm{Pt}$ needs the aid of radicals to enter the gas phase $\left(\mathrm{C}_{2} \mathrm{H}_{4}{ }^{*}, \mathrm{O}_{2} \mathrm{H}^{*}\right)$. The radicals react homogeneously in the gas phase to form clusters, and finally fall back to the surface, producing the "cauliflower" structures. 
(2) Lyubovsky and Barelko [7] studied etching phenomena during ammonia oxidation on $\mathrm{Pt}$ wires partly covered with gold to create (inactive) cold spots. Growth of microcrystals and some kind of "Pt wool" was observed on these spots. The authors suggested that a heterogeneous reaction at active centers induces local heat generation, causing rapid sublimation of Pt from the surface. The deposits were suggested to grow via a vapor-liquid-solid mechanism, where gas phase platinum is trapped by a liquid on colder parts of the surface.

(3) McCabe et al. [21] proposed that platinum is transported from cracks and holes to the surface. Molecular oxygen diffuses into cavities, increasing oxygen activity locally, and forming $\mathrm{PtO}_{2}$. While leaving the holes, most of this oxide decomposes at the surface, resulting in deposits around the cavities. Although this theory might be an explanation for etching of platinum wires, it does not offer a model for formation of "cauliflowers". A phase diagram for the influence of temperature and reactant concentration $\left(\mathrm{NH}_{3}, \mathrm{O}_{2}\right)$ on catalyst etching was reported by McCabe et al. [4] for the temperature range from 700 to $1400{ }^{\circ} \mathrm{C}$.

(4) Nilsen et al. [6] investigated recently thermal and catalytic etching on $\mathrm{Pt}$ and $\mathrm{Pt}_{90} \mathrm{Rh}_{10}$ wires in a flow reactor. During ammonia oxidation, formation of small nodules was detected, which later transformed into cauliflowers. In situ MS revealed $\mathrm{Pt}^{+}, \mathrm{PtO}^{+}$, and $\mathrm{PtO}_{2}{ }^{+}$species to be present in the gas phase. The proposed model suggested active centers for oxidation (preferably on dislocations ending at the surface), local generation of heat and evaporation of $\mathrm{Pt}$ species, and finally growth of protrusions from deposited $\mathrm{Pt}$ via a dendritic growth mechanism. Experiments that exposed $\mathrm{Pt}$ powder to pure oxygen atmosphere in combination with in situ MS confirmed $\mathrm{PtO}_{2}$ as a major vapor species responsible for vapor phase transport of platinum [22].

Ammonia oxidation is a fast and highly exothermic reaction. Thus, previous studies of reaction-induced changes of the surface morphology of Pt were conducted in the ignited regime of ammonia oxidation, where the catalyst temperature is not controlled by the reactor oven, but results mostly from the heat generated in the reaction and its removal. Hence, composition and flow rate of the feed determined the catalyst temperature and imposed a minimum temperature of ca. $600{ }^{\circ} \mathrm{C}$. Moreover, the catalytic reaction was limited by heat and mass transfer in the ignited regime, one possible reason why the cited studies did not report the changes in catalytic activity resulting from the morphological changes. Steep temperature and concentration gradients occur under such reaction conditions, making it difficult to establish the effect of the respective parameters on catalytic etching.

The aim of the present study was to elucidate the influence of temperature on the reconstruction of Pt catalysts induced by ammonia oxidation under temperature-controlled conditions, that is, at lower temperatures than previously accessible, and to observe the associated changes in catalytic activity.
Suitable tools to study the highly exothermic ammonia oxidation are microstructured reactors as proposed by Rebrov et al. [23,24] for supported $\mathrm{Pt} / \mathrm{Al}_{2} \mathrm{O}_{3}$, and recently established by our group for catalytic investigations on polycrystalline Pt foils $[11,25]$. Applying the latter reactor that enabled temperature control in the reaction, product formation was recorded as a function of temperature and time. The Pt samples used as a catalyst for ammonia oxidation at temperatures between 286 and $700{ }^{\circ} \mathrm{C}$ were then characterized by electron microscopy. Based on the data, a relation is established between reaction temperature and the type and extent of changes of surface morphology, as well as the changes in overall catalytic activity.

\section{Experimental}

\subsection{Catalyst}

A thin Pt foil (purity 99.95\%) supplied by Alfa Aesar (Ward Hill MA, USA) was used as a catalyst. The nominal thickness of the foil amounted to $4 \mu \mathrm{m}$. Scanning electron microscopy (SEM) images of the catalyst in the "as-supplied" state (Fig. 1) indicate a smooth surface with small scratches and holes, that is, minimal damage on the fresh samples.

\subsection{Catalytic tests}

Pt foils were applied as catalysts for ammonia oxidation using a microstructured quartz-reactor that assured temperature control. The reactor has been described earlier in detail [11,25]. It allowed measurements with minimal blank activity up to $700{ }^{\circ} \mathrm{C}$, while the kinetic regime prevailed up to ca. $390{ }^{\circ} \mathrm{C}$. Gas composition was continuously monitored downstream of the reactor using a QMS (Balzer Omnistar GCD 300).

The surface morphology of different Pt foil catalysts (Table 1) was studied by SEM after the reaction. To elucidate the influence of reaction temperature and time-on-stream on morphology changes, Pt foils were prepared by exposure to ammonia oxidation (a) at fixed temperatures $\left(286,330,374{ }^{\circ} \mathrm{C}\right)$, and (b) temperature-programmed reaction $\left(20-700{ }^{\circ} \mathrm{C}, 24\right.$ and $240 \mathrm{~h}$, respectively):

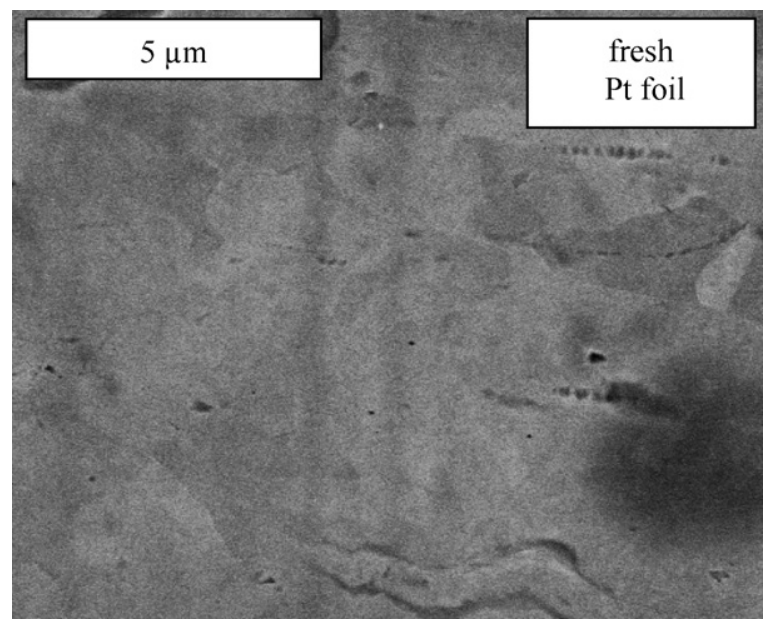

Fig. 1. SEM of fresh Pt foil catalyst, as supplied by Alfa Aesar. 
(a) Three Pt samples used in ammonia oxidation at constant temperatures of 286,330 , and $374{ }^{\circ} \mathrm{C}$, respectively, were prepared applying the following procedure for a total period of time of about $30 \mathrm{~h}$. Catalysts were initially exposed to a feed containing ammonia $(3 \mathrm{kPa})$ and oxygen $(4.5 \mathrm{kPa}$, balance $\mathrm{Ar}$ and $\mathrm{Ne}$ ) of constant composition and temperature for about $12 \mathrm{~h}$ of initial time-on-stream. Thereafter, feed composition was varied at the same temperature between 1 and $6 \mathrm{kPa} \mathrm{NH}, 1$ and $6 \mathrm{kPa} \mathrm{O}_{2}$, adding 0 to $0.47 \mathrm{kPa} \mathrm{NO}$, and 0 to $0.47 \mathrm{kPa} \mathrm{N}_{2} \mathrm{O}$.

(b) Two Pt samples were exposed to temperature-programmed ammonia oxidation between 20 and $700{ }^{\circ} \mathrm{C}$ using a feed mixture $(250 \mathrm{ml} / \mathrm{min})$ containing ammonia $(3 \mathrm{kPa})$ and oxygen $(4.5 \mathrm{kPa}$, balance $\mathrm{Ar}+\mathrm{Ne})$. For one sample, overall activity was followed for $1 \mathrm{~h}$ at each temperature. The temperature ramp was repeated once, resulting in a total time-on-stream of about $24 \mathrm{~h}$. The second sample was studied at each temperature level for about $12 \mathrm{~h}$ during the upramping of temperature, and for $4-12 \mathrm{~h}$ at each temperature level during downramping. Total time-onstream for this catalyst amounted to $240 \mathrm{~h}$ (respective temperatures are indicated in Figs. 3 and 4).

\subsection{Catalyst characterization}

The surface morphology of Pt catalysts was studied by SEM. Images were recorded on a Hitachi-S4000 equipped with FEG (cold) in SE mode. An energy dispersive analyzer (DX 4, EDAX Inc.) equipped with Li-doped Si crystals was attached to the SEM for element analysis (EDX). Electron accelerating voltage for images and spectra was $15 \mathrm{kV}$. SEM images were acquired for different areas of each catalysts surface, exposed either to the catalytic reaction, or covered by the reactor wall.

\section{Results}

\subsection{Overall catalytic activity}

Results of catalytic tests are presented in the order of increasing reaction temperature, starting with experiments at constant temperature of 286,330 , and $374{ }^{\circ} \mathrm{C}$, respectively, followed by temperature-programmed reaction up to $700{ }^{\circ} \mathrm{C}$.

At constant temperatures of 286,330 , and $374{ }^{\circ} \mathrm{C}$, fresh $\mathrm{Pt}$ catalysts were subject to initial activation at all temperatures. The respective relationship between oxygen conversion and time-on-stream is shown in Fig. 2. Since all three experiments were carried out at low temperatures and only moderate oxygen excess as compared to industrial practice, formation of $\mathrm{N}_{2}$ prevailed, selectivity towards nitrogen being between 95 and $99 \%$. Oxygen conversion increased with time-on-stream. The activation progressed faster during an initial period of 2-6 h (Fig. 2), and proceeded slowly thereafter. Moreover, the duration of the initial period of fast activation increased with reaction temperature.

Catalytic results of temperature-programmed ammonia oxidation between 20 and $700{ }^{\circ} \mathrm{C}$ are presented in Figs. 3

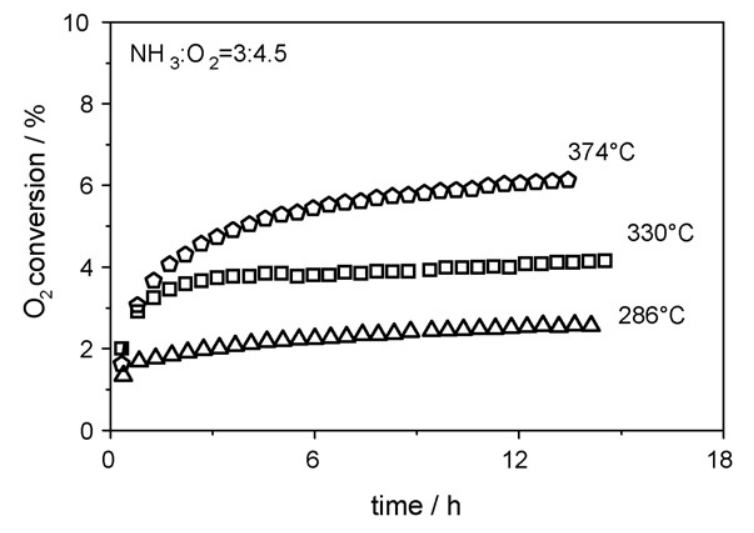

Fig. 2. Oxygen conversion versus time-on-stream in ammonia oxidation over fresh Pt foil at constant temperatures of 286,330 , and $374{ }^{\circ} \mathrm{C}(250 \mathrm{ml} / \mathrm{min}, 3 \%$ $\mathrm{NH}_{3}, 4.5 \% \mathrm{O}_{2}$, balance $\left.\mathrm{Ar}+\mathrm{Ne}\right)$.

and 4 , respectively, as a plot of oxygen conversion versus temperature. The diagrams indicate a hysteresis behavior, where oxygen conversion increased after exposure to high temperature, that is, the Pt catalyst became more active. The activation as reflected by the hysteresis in Fig. 3a was permanent, and progressed further in a second temperature cycle (Fig. 3b). It should be pointed out that only a slight activation was observed during the second temperature cycle (symbols in Fig. 3b) as compared to the first cycle (dashed line in Fig. 3b), indicating that the initial activation in the first temperature cycle progressed significantly faster. Nevertheless, the catalyst became more active in the second cycle.

Hysteresis behavior was also observed in a 20 times slower cycle of temperature-programmed ammonia oxidation that required about $240 \mathrm{~h}$ for completion (Fig. 4). The hysteresis was more marked in this slow temperature cycle (Fig. 4, $t_{\exp }=240 \mathrm{~h}$ ) than in a faster temperature cycle (Fig. 3a, $t_{\exp }=12 \mathrm{~h}$ ), confirming that the extent of activation increases further with increasing time-on-stream.

The difference in overall activity between the heating and the cooling branches of the temperature cycles was only observable at temperatures below approximately $500{ }^{\circ} \mathrm{C}$ (Figs. 3 and 4). Two effects presumably contributed to this behavior: (i) limitation of mass-transfer of the fast reaction begins above ca. $390{ }^{\circ} \mathrm{C}$, diminishing the observable effect of increased catalytic activity, and (ii) the time-on-stream between measurements at the same temperature in both branches of the hysteresis is significantly longer at lower temperatures, that is, activation should be further progressed.

\subsection{Surface morphology}

To elucidate reasons for the observed increase in conversion over the catalyst with time-on-stream in ammonia oxidation, the surface morphology of Pt foils was studied by SEM after exposure to elevated temperatures in absence and presence of the reactive feed. The results are presented first for the absence of feed gases (Section 3.2.1), thereafter for ammonia oxidation in the order of increasing temperature $\left(<374{ }^{\circ} \mathrm{C}\right.$, Section 3.2.2; $<700{ }^{\circ} \mathrm{C}$, Section 3.2.3). 

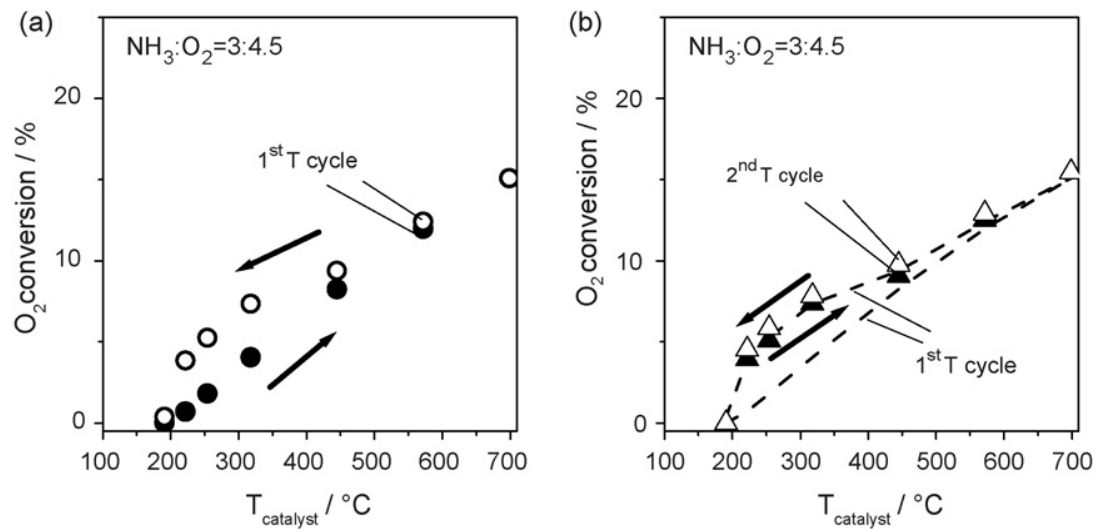

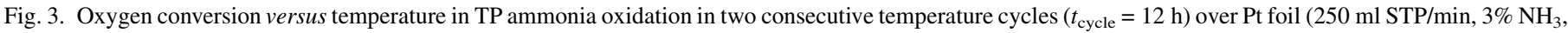

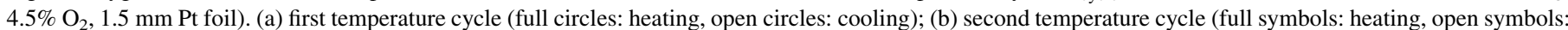
cooling; dashed line: first cycle).

\subsubsection{Pt foil after temperature treatments up to $700{ }^{\circ} \mathrm{C}$ in absence of reactive atmosphere}

SEM micrographs of $\mathrm{Pt}$ foils treated for about $30 \mathrm{~h}$ at $374{ }^{\circ} \mathrm{C}$ are shown in Fig. 5a, and for a temperature-program of 20 $700{ }^{\circ} \mathrm{C}$ for a total duration of $240 \mathrm{~h}$ in Fig. 5b, respectively. Both samples were covered by the quartz-plates of the reactor wall during the temperature treatment, and therefore not exposed to the reactive atmosphere of ammonia oxidation. Compared to the image of a fresh platinum foil (Fig. 1) the surface appears to be basically unchanged. Thus, the respective thermal treatments of $\mathrm{Pt}$ foil did not alter its surface morphology, and the process of thermal etching of platinum is concluded to be negligibly slow under the conditions of the present study.

\subsubsection{Pt foil after catalytic ammonia oxidation at constant temperatures of $286-374{ }^{\circ} \mathrm{C}$}

The area of Pt foils being catalytically active in ammonia oxidation at constant temperature levels are shown in Fig. 6 for the reaction at $286{ }^{\circ} \mathrm{C}$ (Fig. $6 \mathrm{a}$ and b), $330{ }^{\circ} \mathrm{C}$ (Fig. 6c and d), and $374{ }^{\circ} \mathrm{C}$ (Fig. 6e and f). Already the sample catalyzing the

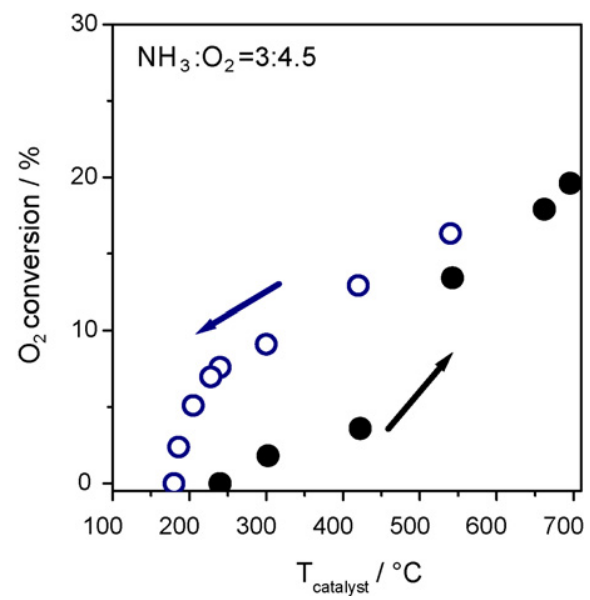

Fig. 4. Oxygen conversion versus temperature in TP ammonia oxidation $\left(t_{\exp }=240 \mathrm{~h}\right)$ over fresh Pt foil; $250 \mathrm{ml} \mathrm{STP} / \mathrm{min}, 3 \% \mathrm{NH}_{3}, 4.5 \% \mathrm{O}_{2}$, $1.3 \mathrm{~mm}$ Pt foil full circles: heating open circles: cooling. reaction at the lowest temperature of $286^{\circ} \mathrm{C}$ expressed an altered morphology. Some areas appeared rougher after reaction, while others were not visibly changed (Fig. 6b). Roughening seems to have started from grain boundaries, perhaps due to a less ideal surface, and a locally increased defect concentration. The surface modifications exhibited the same orientation in neighboring areas.

At the higher reaction temperature of $330{ }^{\circ} \mathrm{C}$ etching of the catalyst surface occurred in wider areas (Fig. 6c and d), although some parts of the surface remained still unchanged in the SEM images. Moreover, the individual structures increased in size (Fig. 6b/d), and appeared as parallel rows of facets. The majority of facets formed at $330{ }^{\circ} \mathrm{C}$ were similar in size (Fig. 6d). Moreover, the facets locally possess the same orientation. However, different facet orientations existed along the foil sample (not shown).

The sample of $\mathrm{Pt}$ foil that was exposed to ammonia oxidation at $374{ }^{\circ} \mathrm{C}$ (Fig. 6e and f) featured a fully restructured and ordered surface, in contrast to platinum which had been used as catalyst at lower temperatures. The structures covered the complete surface (Fig. 6e), and were arranged in parallel rows of facets, each of them about $0.5 \mu \mathrm{m}$ apart (Fig. 6f). Each row consisted of smaller shapes that resembled roofs, made up of flat planes and connected by sharply defined edges. The "roofs" look like welldefined single crystal faces, and are supposed to be thermodynamically stable low-index crystal planes. Some facets were penetrated by holes of a square shape, and less than $0.1 \mu \mathrm{m}$ in diameter (Fig. 6f).

The same dominating orientation of the facets was observed over large (reaction-exposed parts of the) Pt sample, covering an area of at least $40 \mu \mathrm{m} \times 60 \mu \mathrm{m}$. Only occasionally the order of parallel facets was locally disturbed, and the same type of facet rows appeared rotated by about $90^{\circ}$ (left part of Fig. 6e), or sometimes $45^{\circ}$. The rotated facet rows terminated flat slabs of Pt of about $0.5 \mu \mathrm{m}$ thickness (Fig. 6e).

\subsubsection{Pt foil after temperature-programmed ammonia oxidation between 20 and $700{ }^{\circ} \mathrm{C}$}

SEM micrographs of the surface of Pt foils after catalysis in temperature cycles from 20 to $700{ }^{\circ} \mathrm{C}$ for a total duration 

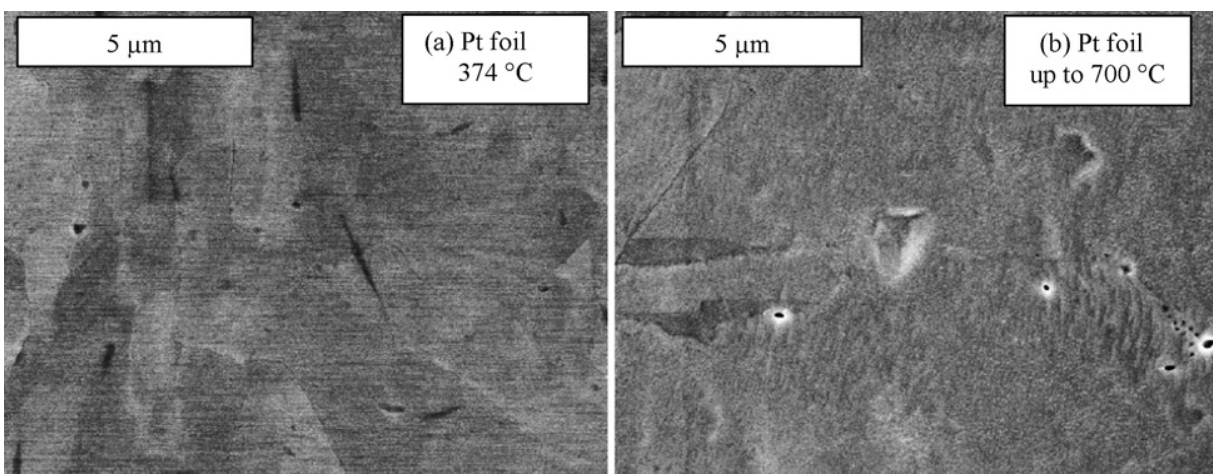

Fig. 5. SEM of platinum foil after exposure to reaction temperature, but not to the reactants of ammonia oxidation (surface of the Pt foil was protected from gases by plates of quartz glass). (a) at constant temperature of $374{ }^{\circ} \mathrm{C}$ for $30 \mathrm{~h}$; (b) at $20-700{ }^{\circ} \mathrm{C}$ for a total of $240 \mathrm{~h}$.

of $24 \mathrm{~h}$ and for $240 \mathrm{~h}$ are shown in Fig. 7a/b and in Fig. 7c/d, respectively. The conditions applied to the reaction exposure for $24 \mathrm{~h}$ (Fig. 7a,b) differed from the previous samples (Fig. 6) not so much in the exposure time (24 h vs. $30 \mathrm{~h})$, but most of all in the maximum temperature $\left(700{ }^{\circ} \mathrm{C}\right.$ vs. $286-$ $\left.330{ }^{\circ} \mathrm{C}\right)$.

After $24 \mathrm{~h}$ of time-on-stream the $\mathrm{Pt}$ surface featured somehow parallel rows of facets in some areas (Fig. 7a, right
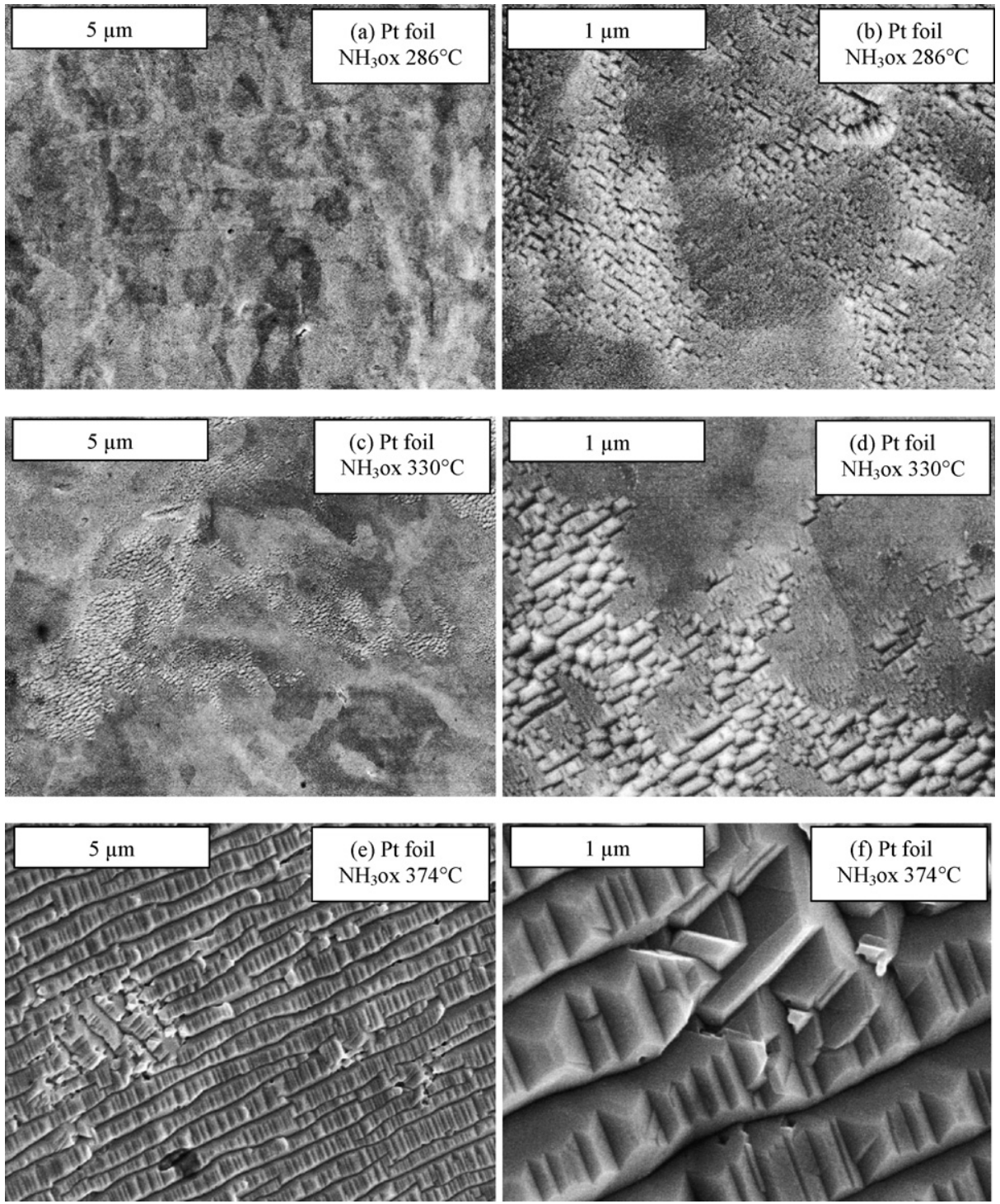

Fig. 6. SEM of platinum foil after ammonia oxidation at constant temperature: (a,b) $30 \mathrm{~h}$ at $286{ }^{\circ} \mathrm{C}$; (c,d) $30 \mathrm{~h}$ at $330{ }^{\circ} \mathrm{C}$; (e,f) $30 \mathrm{~h}$ at $374{ }^{\circ} \mathrm{C}$. 

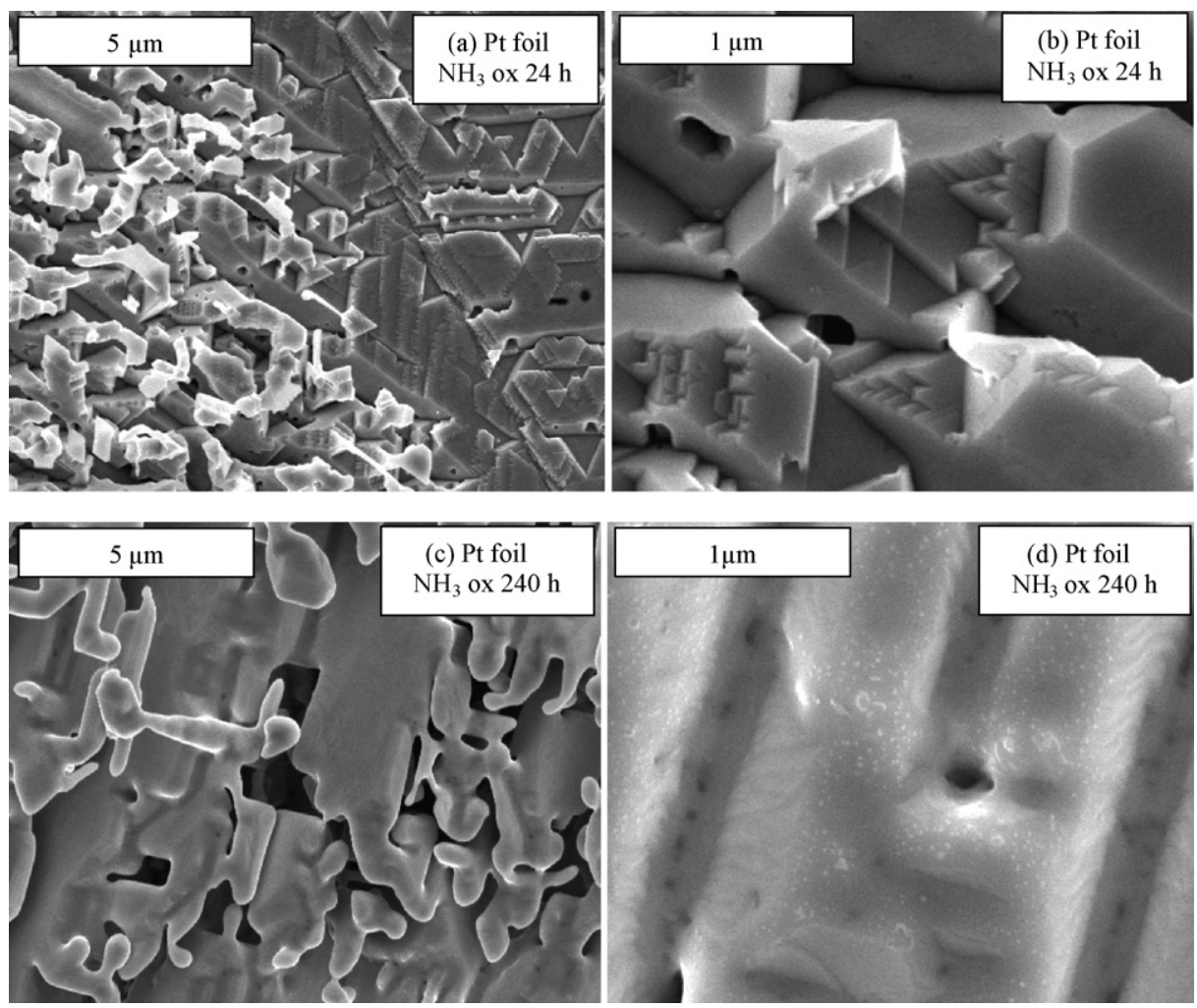

Fig. 7. SEM of platinum foil after temperature-programmed ammonia oxidation: (a,b) at $20-700{ }^{\circ} \mathrm{C}$ for a total of $24 \mathrm{~h}$; (c,d) at $20-700{ }^{\circ} \mathrm{C}$ for a total of $240 \mathrm{~h}$.

side), but the previously observed (Fig. 6) well-defined roof structures did not exist. Moreover, facet rows were about $2 \mu \mathrm{m}$ wide, compared to less than $0.5 \mu \mathrm{m}$ at 286 to $374{ }^{\circ} \mathrm{C}$. In some areas (Fig. 7a, left side) the surface reconstructed into bulky and three-dimensional structures protruding from the surface. Furthermore, the formed facet rows were deep and undercut. Numerous holes penetrated the protrusions (Fig. 7b), and reached sizes similar to the dimensions of the crystals growing from the surface. Such crystals consisted of flat faces and sharp edges (Fig. 7b), but some of the sharp edges were faceted themselves. Compared to the low-temperature samples, the appearance of the Pt surface became rougher, disordered and porous.

The three-dimensional reconstruction of the $\mathrm{Pt}$ catalyst (Fig. 7b) progressed further in a period of $240 \mathrm{~h}$ of ammonia oxidation up to $700{ }^{\circ} \mathrm{C}$ (Fig. 7c and d), and resulted in loosely connected crystals (Fig. 7c). Instead of flat faces and straight edges, the protrusions looked smooth and rounded, where the

Table 1

List of Pt foil samples, used for ammonia oxidation and SEM characterization

Sample name Description of sample treatment

Pt foil $\mathrm{NH}_{3}$ ox $286^{\circ} \mathrm{C}$ Pt foil $\mathrm{NH}_{3}$ ox $330{ }^{\circ} \mathrm{C}$

(a) Fresh Pt foil, ammonia oxidation, $286^{\circ} \mathrm{C}, 30 \mathrm{~h}$ Pt foil $\mathrm{NH}_{3}$ ox $374^{\circ} \mathrm{C}$

Pt foil TP- $\mathrm{NH}_{3}$ ox $24 \mathrm{~h}$

(a) Fresh Pt foil, ammonia oxidation, $330^{\circ} \mathrm{C}, 30 \mathrm{~h}$

(a) Fresh Pt foil, ammonia oxidation, $374{ }^{\circ} \mathrm{C}, 30 \mathrm{~h}$

(b) Fresh Pt foil, $\mathrm{H}_{2}$ treated, ammonia oxidation,

two temperature ramps $20-700-20{ }^{\circ} \mathrm{C}$, total time $24 \mathrm{~h}$

Pt foil TP- $\mathrm{NH}_{3}$ ox $240 \mathrm{~h}$ (b) Fresh Pt foil, ammonia oxidation, one temperature ramp $20-700-20{ }^{\circ} \mathrm{C}$, total time $240 \mathrm{~h}$ underlying shape of a wellformed crystals was only faintly visible (Fig. 7c). The crystals were several micrometers in size, and were connected to other crystals only via narrow bridges. Due to the porous surface morphology, and the small remaining connections between the Pt crystals, it is likely that heat conduction through the catalyst becomes severely obstructed, and local temperature gradients form due to the exothermic reaction.

\section{Discussion}

The reaction-induced changes of catalytic activity are discussed below (Section 4.1), followed by differences in observed surface morphologies (Section 4.2), and influences governing the surface restructuring (Section 4.3). Finally, the results are related to possible mechanisms of platinum transport (Section 4.4).

\subsection{Reaction-induced changes of overall activity of the catalysts}

Platinum foils became more active during catalytic ammonia oxidation under all investigated conditions, that is, during the reaction at constant temperatures of $286-374{ }^{\circ} \mathrm{C}$ (Fig. 2) as well as during temperature ramps to $700{ }^{\circ} \mathrm{C}$ (Figs. 3 and 4). Moreover, SEM images indicate that all of the activated catalysts developed a reconstructed surface during this activation process (Figs. 6 and 7), changing from a flat initial surface to different expressions of a roughened morphology. Hence, the presumably associated increase in 
the surface area of Pt catalysts is one effect that could account for the observed reaction-induced increase in overall catalytic activity. Nevertheless, etching of the Pt foils did not progress uniformly across the surface (Fig. 6b and d; Fig. 7a). It is therefore likely that the intrinsic activity of the Pt catalysts varied over the surface. Since the catalytic measurements of ammonia oxidation represented a sum of reactivity over the whole catalyst, local differences in activity could not be investigated.

Both, initial activation of the polycrystalline Pt catalyst as well as roughening of the Pt surface started at surprisingly low temperatures $\left(286{ }^{\circ} \mathrm{C}\right)$ that were not accessible in previous studies of catalytic etching of platinum. Moreover, product formation in the catalytic ammonia oxidation (reactant partial pressures in the $\mathrm{kPa}$ range) started around $200{ }^{\circ} \mathrm{C}$ (Fig. 3). Thus, the temperature range, where possibly no significant reactioninduced restructuring of the platinum surface occurs is very narrow.

In contrast to earlier studies, the reaction-induced changes in the overall activity of polycrystalline Pt were investigated in the present work in a temperature-controlled way, and at oxygen conversions below 20\%. Hence, direct evidence for a link between the activation of $\mathrm{Pt}$ with time-on-stream and faceting of the Pt surface was obtained for the first time, while previous reports [26] were limited to the discussion of selectivity and yield measured at full ammonia conversion in the ignited regime of the reaction.

\subsection{Morphology of restructured Pt surfaces}

The roughening of $\mathrm{Pt}$ catalysts due to ammonia oxidation was observed in different expressions, that is, rows of parallel facets (Fig. 6d and f), pits (Fig. 6f, Fig. 7b and d), and bulky crystals growing from the surface (Fig. $7 b$ and c). Similar surface structures have been reported in literature such as facet rows $[4,6,7,12,15]$, pits $[4,12,15]$, and bulky crystals protruding from the surface $[6,7,12]$. In contrast, so-called "cauliflower" structures were reported for Pt gauzes after more than $330 \mathrm{~h}$ time-on-stream in ammonia oxidation [6,12,27], but not observed in the present study that was conducted at lower temperatures and time-on-stream.

Surface structures reported in literature differed from those in the present work in size, especially for Pt samples that were exposed to the lower reaction temperatures of 286 to $374{ }^{\circ} \mathrm{C}$. While parallel rows of facets less than $0.1 \mu \mathrm{m}$ apart from each other were formed in our experiments (Fig. $6 b$ and d), the reported width of facet rows always exceeded $0.5 \mu \mathrm{m}$ $[4,6,7,12,15]$. Moreover, also the assembly of facet rows from the sharply defined flat faces shown in Fig. $6 f$ has not been reported yet to our knowledge. Such a difference can be ascribed to two reasons. First of all, the SEM images presented in this work are of higher resolution than shown by other authors. More importantly, temperature is a major parameter in the catalytic etching of $\mathrm{Pt}$, and the present experiments were carried out at temperatures significantly below the $600{ }^{\circ} \mathrm{C}$, which represented the lower temperature limit of earlier work on Pt spheres and wires.
As evidenced by several of the SEM images (Fig. $6 \mathrm{~b}$ and $\mathrm{d}$, Fig. 7a), ammonia oxidation did not roughen all areas of the $\mathrm{Pt}$ surface to the same extent. Literature reports agree with the finding that initial etching of the Pt surface is not uniform over the whole surface of polycrystalline Pt $[4,12]$, but vary in the observation that whole grains were fully covered by similar facets [4] or etching started near grain boundaries [7,12]. The present data supports the view that etching of the Pt surface spreads from grain boundaries. Preferred restructuring near grain boundaries may result from a locally increased concentration of defects in such areas and disturbance of lattice regularity, which results in a variation of the corresponding reaction rates of the structure sensitive ammonia oxidation.

All SEM images of restructured $\mathrm{Pt}$ wires and spheres provided by other authors $[4,6,7,12]$ featured different facet orientations in neighboring areas on the surface. In contrast, the studied Pt foil exhibited the same preferred facet orientation (Fig. 6e) over a range of at least $40 \mu \mathrm{m} \times 60 \mu \mathrm{m}$ after ammonia oxidation at $374{ }^{\circ} \mathrm{C}$ (not shown). A definite explanation for the uniform faceting over such a large area cannot be given yet, since it is not known if the initial crystallite orientation on the fresh Pt foil was the same over the whole surface. It is suggested that the resulting facet orientation is either determined by a texture present in the fresh Pt sample from its manufacturing process, or from the flow direction of the feed mixture over the sample.

\subsection{Influence of gas atmosphere, temperature, and time- on-stream on surface restructuring}

Images of the surface after catalytic ammonia oxidation (Fig. 6e, Fig. 7c) were compared to those of samples that were exposed to the identical temperature treatment (Fig. 5a and b), but in the absence of any reactive gas atmosphere. While the latter samples resembled the surface of untreated $\mathrm{Pt}$ foil (Fig. 1), only the morphology of Pt exposed to the catalysis of ammonia oxidation became rough and restructured. Hence, the presence of reactive adsorbates on the surface is essential for restructuring of $\mathrm{Pt}$ catalysts between 286 and $700{ }^{\circ} \mathrm{C}$. Therefore, the process of changing the surface morphology can be classified as "catalytic etching", and not as thermal etching.

A comparison between SEM images of Pt samples that were applied in ammonia oxidation at different temperatures of 286, 330, and $374{ }^{\circ} \mathrm{C}$ for the same time-on-stream (Fig. 6b, d, and f), showed that in this temperature range similar shapes of facets formed on the surface. The size of facet rows clearly increased with temperature from less than $0.1 \mu \mathrm{m}$ at $286{ }^{\circ} \mathrm{C}$ to about $0.5 \mu \mathrm{m}$ at $374{ }^{\circ} \mathrm{C}$ (Fig. 6b, d, and f). Moreover, also the area that developed facets increased in this temperature range up to a fully facetted surface at $374{ }^{\circ} \mathrm{C}$ (Fig. 6b, d, and f). Hence, temperature is a major parameter that determines both facet size as well as surface coverage with facets in ammonia oxidation between 286 and $374{ }^{\circ} \mathrm{C}$. In contrast to this present conclusion, previous work of McCabe et al. [4] reported only a "weak correlation" between facet size, which was between 0.5 and $3 \mu \mathrm{m}$, and temperature for experiments conducted at 700 to 
$1400{ }^{\circ} \mathrm{C}$. As mentioned before, the differences may be attributed to better temperature control in the current reactor setup, and the fact that the present correlation was established for significantly lower reaction temperatures.

In contrast to the parallel rows of facets observed after reaction at 286 to $374{ }^{\circ} \mathrm{C}$, where the facetted surface remained essentially flat (Fig. 6b, d, and f), bulky crystals of different shapes protruding from the surface formed in temperatureprogrammed ammonia oxidation up to $700{ }^{\circ} \mathrm{C}$ (Fig. $7 \mathrm{~b}$ and c). Moreover, also the shape of the occasionally observed pits changed from straight-edged and square-shaped (Fig. 6f) towards a more rounded appearance (Fig. $7 b$ and d). This variation in surface morphology occurred despite of the fact that the time of exposure to ammonia oxidation at $286-374{ }^{\circ} \mathrm{C}$ ( $30 \mathrm{~h}$, Fig. 6) was comparable to that of one high-temperature sample ( 24 h, Fig. 7a and b). Hence, the shift from temperatures below $400{ }^{\circ} \mathrm{C}$ to about $700{ }^{\circ} \mathrm{C}$ resulted in a change of surface morphology towards bulky crystals and a porous surface appearance, that is, a completely different restructuring of Pt. Thus, temperature is of major importance over the whole studied temperature range of ammonia oxidation. Moreover, the essential differences in Pt structures formed below and above $400{ }^{\circ} \mathrm{C}$ also suggest a corresponding change in the dominating mechanism of $\mathrm{Pt}$ transport that is discussed in Section 4.4.

As concluded in Section 4.1, the initial activation of $\mathrm{Pt}$ at 286-374 ${ }^{\circ} \mathrm{C}$ progressed faster than at later stages (Fig. 2). Moreover, also in the temperature-programmed reaction up to $700{ }^{\circ} \mathrm{C}$ the activation was more marked in the initial first temperature cycle (Fig. 3a) than in the second cycle (Fig. 3b). The data suggest that the etching process slows down after reaching a more stable surface configuration during the initial time-on-stream.

To the best of our knowledge, rates of progressing activity changes of Pt during ammonia oxidation have not been reported in literature. Nevertheless, some authors presented SEM images of Pt wires after different times-on-stream under ignited (i.e. transfer-limited, full-conversion) conditions of the reaction. While Hannevold et al. [12] concluded that the size of facet rows and bulky crystals grows with time-on-stream, Lyubovsky and Barelko [7] observed a sequential two-step process where first facet rows are formed, and thereafter crystals grow from the surface. Since we did not image the Pt surface at different times, we cannot directly confirm or deny those previous reports. Nevertheless, catalyst activation progressed in two phases of fast initial, and slow further activation at $286-374{ }^{\circ} \mathrm{C}$. However, this behavior cannot be explained by the two stages of surface roughening proposed by Lyuboski and Barelko, since only flat facets were observed on the surface at such temperatures (Fig. 6). More frequent SEM observations of the Pt surface during time-on-stream would be required to elucidate the kinetics of surface restructuring.

\subsection{Mechanism of platinum transport}

Based on the knowledge that Pt can be transported in oxygen atmosphere as volatile platinum oxide, and the fact that $\mathrm{PtO}_{x}$ species were identified by MS to be present under conditions of ammonia oxidation at $\mathrm{Pt}$ wires at temperatures above $600{ }^{\circ} \mathrm{C}$, the vapor of Pt oxide was previously concluded to be the major species responsible for platinum transport through the gas phase during ammonia oxidation $[6,12,21,22]$. Bulky crystals, and finally cauliflowers were assumed to grow upon oxide decomposition and Pt redeposition on the surface [6,12,22]. The same mechanism probably leads also to the growth of bulky crystals that were observed in the present study after temperature ramps to $700{ }^{\circ} \mathrm{C}$ (Fig. 7). Since we did not evaluate the gas phase species present over the catalyst in situ, further evidence on the presence of vapor of thermodynamically instable Pt oxides, and the temperatures at which they are formed, cannot be provided.

Reaction-induced reconstruction of the Pt surface occurred already at a temperature of $286{ }^{\circ} \mathrm{C}$ (Fig. 6b), a temperature significantly below the ca. $800{ }^{\circ} \mathrm{C}$ reported to be required for obtaining significant rates of $\mathrm{PtO}_{x}$ evaporation in oxygen atmosphere [16,28]. Hence, transport of Pt through the gas phase is unlikely to be an important transport mechanism below $400{ }^{\circ} \mathrm{C}$. Moreover, the reconstructed Pt surface after ammonia oxidation at $286-374{ }^{\circ} \mathrm{C}$ developed into flat and ordered facets, but did not show any sign of the bulky microcrystals protruding from the surface at higher temperatures. Thus, a mechanism of $\mathrm{Pt}$ transport may be in operation different from that involving volatile $\mathrm{PtO}_{2}$.

Since Pt reconstructed only in the presence of reactants (Figs. 6 and 7), but not during simple temperature treatments (Fig. 5), it is unlikely that surface or bulk diffusion of Pt atoms can account for the formation of facets. The required presence of the feed mixture containing oxygen and ammonia suggests that adsorbates provide $\mathrm{Pt}$ atoms with the mobility or driving force necessary for facet formation. As demonstrated by Horch et al. [29], hydrogen is a possible candidate that enhances the diffusion rate of $\mathrm{Pt}$ atoms on a $\mathrm{Pt}\left(\begin{array}{lll}1 & 1 & 0\end{array}\right)$ surface up to 500 times at room temperature $\left(p_{\mathrm{H} 2}=7 \times 10^{-7} \mathrm{mbar}\right)$ when monitored by STM, interpreted as lowering of the respective energy barrier. Moreover, also ammonia was reported to increase the surface mobility of step atoms on a $\operatorname{Pt}(443)$ surface in such a way that the straight step edges completely dissolved within $15 \mathrm{~min}$ at room temperature $\left(p_{\mathrm{NH} 3}=10^{-6} \mathrm{mbar}\right)$ [30].

At the relatively high pressures $\left(p_{\mathrm{NH} 3}=3 \mathrm{kPa}\right)$ and low temperatures of the present work $\left(286-374{ }^{\circ} \mathrm{C}\right)$ a significant coverage of the $\mathrm{Pt}$ surface with reaction intermediates of ammonia oxidation should be expected. It is therefore proposed that the restructuring, which was induced on the surface of $\mathrm{Pt}$ foil during ammonia oxidation between 286 and $374{ }^{\circ} \mathrm{C}$ (Fig. 6) is facilitated by the presence of adsorbates, that is, reaction intermediates of the ammonia oxidation. Such possible reaction intermediates can be adsorbed ammonia as well as other $\mathrm{NH}_{x}$ species [31]. An increase in reaction temperature would thus promote two opposing effects: on one hand higher temperatures accelerate diffusion rates on the surface, on the other hand adsorbate coverage decreases due to faster desorption, and the surface faceting would be hindered.

Summarizing the above discussion, temperature is suggested to be a major parameter controlling the reaction-induced 
surface reconstruction of $\mathrm{Pt}$ under conditions of ammonia oxidation in various ways: via the kinetics of ammonia oxidation, temperature determines the adsorbate coverage of the surface, and hence a possible adsorbate-related mobility enhancement of $\mathrm{Pt}$ surface atoms. Moreover, temperature determines also the rate of formation of volatile Pt oxide, that is, the rate of Pt transport through the gas phase. By influencing the rates of both discussed ways of $\mathrm{Pt}$ transport, temperature is suggested to control which transport mechanism is dominant, and hence, if flat facets or protruding bulky crystals are formed.

\section{Conclusions}

The temperature-control in catalytic ammonia oxidation at reactant partial pressures of several kilopascals, established by the use of a microstructured reactor, allowed to investigate the influence of temperature and time on the reaction-induced changes of polycrystalline Pt and the related changes in overall catalytic activity. The surface of Pt foil restructured already at the surprisingly low temperature of $286{ }^{\circ} \mathrm{C}$. This strong sensitivity of $\mathrm{Pt}$ catalysts towards the reaction environment emphasizes the need for thorough surface characterization in catalytic and kinetic studies of ammonia oxidation. Since facets significantly smaller than previously reported were observed, a sufficiently high resolution of electron microscopy images is required.

Temperature and time-on-stream were established as the major parameters that determine the morphology of Pt foil after ammonia oxidation, and led to changes in its surface structure throughout the studied temperature range of $286-700{ }^{\circ} \mathrm{C}$. Moreover, comparing catalyst samples after thermal treatment with those exposed to the reaction confirmed, that for the present conditions etching of the Pt surface was induced only by a combination of reaction and elevated temperature.

The reaction temperature influenced the morphology of $\mathrm{Pt}$ catalyst in a characteristic way: at low temperature (286$374{ }^{\circ} \mathrm{C}$ ) only flat facets were formed, while at higher temperatures (up to $700{ }^{\circ} \mathrm{C}$ ) bulky structures grew from the previously flat surface. From the pronounced differences in formed Pt morphologies, and the fact that faceting started well below temperatures at which Pt is oxidized and evaporated at a significant rate, an additional mechanism different from the gas phase transport via volatile platinum oxide was suggested to be in operation between 286 and $374{ }^{\circ} \mathrm{C}$. Adsorbate-enhanced surface diffusion was proposed as one possible mechanism of Pt transport.

Further studies are suggested to focus on elucidating the mechanism that governs platinum transport at temperatures below $400{ }^{\circ} \mathrm{C}$, for example, DFT calculations or in situ microscopic investigations. The kinetics of morphology changes could be established by following the faceting versus time-on-stream for different temperatures and feed compositions. Moreover, relations between product selectivity in ammonia oxidation and surface faceting need to be investigated by experiments carried out with feed mixtures of higher oxygen content, that is, under conditions of enhanced $\mathrm{NO}$ and $\mathrm{N}_{2} \mathrm{O}$ formation.

\section{Acknowledgements}

This work was supported by DFG's priority program SPP 1019 "Bridging the gap between real and ideal systems in heterogeneous catalysis". The provision of SEM images by G. Weinberg and R. Schlögl is gratefully acknowledged.

\section{References}

[1] L.D. Schmidt, D. Luss, J. Catal. 22 (1971) 269

[2] G.R. Gillespie, R.E. Kenton, Chem. Tech. 1 (1971) 627.

[3] T.C. Wei, J. Phillips, Adv. Catal. 4 (1996) 359.

[4] R.W. McCabe, T. Pignet, L.D. Schmidt, J. Catal. 32 (1974) 114.

[5] E. Bergene, O. Tronstadt, A. Holmen, J. Catal. 160 (1996) 141.

[6] O. Nilsen, A. Kjekshus, H. Fjellvag, Appl. Catal., A: General 207 (2001) 43.

[7] M.R. Lyubovsky, V.V. Barelko, J. Catal. 149 (1994) 23.

[8] Z. Yang, Y. Ning, H. Zhao, J. Alloys Compd. 218 (1995) 51.

[9] T. Pignet, L.D. Schmidt, J. Catal. 40 (1975) 212.

[10] J.L. Gland, V.N. Korchak, J. Catal. 53 (1978) 9.

[11] M. Baerns, R. Imbihl, V.A. Kondratenko, R. Kraehnert, W.K. Offermans, R.A. van Santen, A. Scheibe, J. Catal. 232 (2005) 226.

[12] L. Hannevold, O. Nilsen, A. Kjekshus, H. Fjellvag, Appl. Catal., A: General 284 (2005) 163.

[13] D.R. Anderson, J. Catal. 113 (1988) 475.

[14] P.A. Kozub, G.I. Gryn, I.I. Goncharov, Platinum Met. Rev. 44 (2000) 74.

[15] M. Flytzani-Stephanopoulos, S. Wong, L.D. Schmidt, J. Catal. 49 (1977) 51.

[16] R.W. Bartlett, J. Electrochem. Soc. 114 (1967) 547.

[17] E.J. Nowak, Chem. Eng. Sci. 24 (1969) 421.

[18] N.L. Wu, J. Phillips, J. Catal. 113 (1988) 129.

[19] J.M. Hess, J. Phillips, J. Catal. 136 (1992) 149.

[20] V.W. Dean, M. Frenklach, J. Phillips, J. Phys. Chem. 92 (1988) 5731.

[21] A.R. McCabe, C. Wong, H.S. Woo, Platinum Met. Rev. 30 (1986) 54.

[22] L. Hannevold, O. Nilsen, A. Kjekshus, H. Fjellvag, J. Cryst. Growth 279 (2005) 206

[23] E.V. Rebrov, M.H.J.M. de Croon, J.C. Schouten, Catal. Today 69 (2001) 183.

[24] E.V. Rebrov, M.H.J.M.d. Croon, J.C. Schouten, Chem. Eng. Res. Des. 81 (2003) 744.

[25] N. Dropka, K. Jähnisch, E.V. Kondratenko, V.A. Kondratenko, R. Kraehnert, N. Steinfeldt, D. Wolf, M. Baerns, Int. J. Chem. React. Eng. 3 (2005) 51.

[26] P.A. Kozub, N.V. Trusov, G.I. Gryn, V.V. Prezhdo, J. Chem. Technol. Biotechnol. 76 (2001) 147.

[27] E. Bergene, doctoral thesis, Surface Characterisation of $\mathrm{Pt}$ and $\mathrm{Pt} / \mathrm{Rh}$ Gauze Catalysts, Universitet I Trondheim, Trondheim, 1990.

[28] G.C. Fryburg, H.M. Petrus, J. Electrochem. Soc. 108 (1961) 496.

[29] S. Horch, H.T. Lorensen, S. Helveg, E. Laegsgaard, I. Stensgaard, K.W. Jacobsen, J.K. Norskov, Nature 398 (1999) 134.

[30] A. Scheibe, doctoral thesis, Gestufte Platineinkristalloberflaechen als Modellsystem fuer die katalytische Ammoniakoxidation mit Sauerstoff, Universitaet Hannover, Hannover, 2003.

[31] W.K. Offermans, A.P.J. Jansen, R.A. van Santen, Surf. Sci. 600 (2006) 1714. 